\title{
Mercantilização do ensino: a percepção dos docentes do ensino superior privado no Brasil
}

\author{
Míriam Rabelo Gontijo ${ }^{1}$ \\ Fernando Coutinho Garcia ${ }^{2}$
}

\section{Resumo}

Este artigo buscou analisar a vida profissional de docentes da educação superior de grandes grupos privados, com unidades em Belo Horizonte, Minas Gerais, diante da crescente "empresarialização" (DEMO, 2007) do ensino no Brasil. O objetivo principal do estudo foi caracterizar a vida profissional desses professores, que vêm atuando em instituições cada vez mais similares a qualquer outro tipo de empresa, com metas e prazo pré-estabelecidos e tarefas padronizadas a serem cumpridas, o que às vezes os privam da autonomia e criatividade em seu trabalho. Para se chegar aos resultados da pesquisa, utilizou-se uma abordagem qualitativa, com o método histórias de vida (ATKINSON, 2002). Seis docentes que trabalham ou trabalharam no ensino superior privado de grandes grupos educacionais foram convidados a falar sobre sua trajetória profissional. O tratamento dos dados se deu pela análise de conteúdo (BARDIN, 1979). Os resultados mostraram que os grandes grupos educacionais têm investido em programas informatizados que vêm não somente substituindo o trabalho presencial do docente por plataformas, como também engessando o trabalho desses professores. Os docentes, segundo seus relatos, sentem-se desamparados e desvalorizados por suas instituições. Os sistemas de gerenciamento institucionais ainda servem como ferramentas remotas de vigilância e "adestramento" (MENDONÇA NETO; ANTUNES; VIEIRA, 2012), utilizados não somente com finalidades pedagógicas, mas também para controlarem o trabalho cotidiano dos professores. Além deles, diversas formas de precarização e intensificação de esforços docentes podem ser derivadas da busca por lucros dessas grandes instituições, agora comumente chamadas de companhias.

Palavras-chave: Docente. Instituições de Ensino Superior Privado. Precarização. Intensificação. Sistemas de Gerenciamento Informatizados

\section{INTRODUÇÃO}

O mundo do trabalho vem sofrendo diversas modificações nas últimas décadas (DAHL, 2001), com alterações estruturais, tecnológicas, produtivas e organizacionais (GOMES, 2002). O capitalismo, até chegar à forma como é conhecido hoje, passou por uma série de mudanças e adaptações entre os anos 60 e 70, que culminaram em formas de trabalho bem diferentes daquelas praticadas no sistema fordista, que entrou em declínio por razões de ordem econômica em nível global (BOLTANSKY; CHIAPELLO, 2009). Essas mudanças não ocorreram apenas em nível industrial. Outros setores, como o educacional, vêm

\footnotetext{
${ }^{1}$ Graduada em Letras, Pós-graduada em Ensino de Língua Inglesa, Mestre em Administração, com pesquisa na área de gestão de instituições de ensino superior. Experiência como coordenadora de extensão e pós-graduação e docência no ensino superior. miriamrgontijo@ hotmail.com

${ }^{2}$ Doutor em Ciência Política pela USP e professor do Programa de Mestrado da Unihorizontes.
} 
acompanhando as alterações nas formas de trabalho. A educação, antes garantida aos cidadãos em sua maior parte pelo Estado, passou, aos poucos, a compor o setor de serviços não mais exclusivos desse mesmo Estado por meio da privatização. Com isso, um dos direitos sociais mais importantes passou a ser amplamente comercializado no país. As instituições educacionais, com seus novos modelos de gestão e ensino voltados para as necessidades do mercado, vêm fragilizando as relações de trabalho, já que estão ligadas à gestão de receita e metas (CHAUÍ, 2003).

Ferreira, Nascimento e Salvá (2014) afirmam que a mercantilização do ensino se deu por meio de reformas educacionais que ocorreram a partir do governo Collor (1990-1992), quando se começou a utilizar a privatização no programa econômico do país para a contenção de gastos. Esses programas tiveram sequência nos governos seguintes e, em 1996, Fernando Henrique Cardoso, com a criação da Lei de Diretrizes e Bases, permitiu que a privatização abarcasse o ensino superior. Essas reformas propiciaram a expansão do setor educacional privado, principalmente pela adoção de programas de concessão de bolsas, ensejadas no governo Lula (2003-2010) e que se estendem até o momento atual, sofrendo modificações em suas regras de acordo com o cenário econômico de cada época.

O aumento de alunos nas instituições, ocasionado pelos benefícios concedidos pelo governo, acabou criando empresas gigantes no ramo educacional. Grandes grupos, como Kroton, Estácio, Anima, Ser Educacional, que atuam essencialmente no segmento educacional e ainda grupos como o Splice, que atuam em mercados variados, têm atraído grande parcela dos alunos do ensino superior, fomentando um mercado cujo faturamento chegou a 13 bilhões, em 2013 (HOPER, 2013). No entanto, na visão de Nogueira e Oliveira (2015, p. 336), a transformação da universidade em empresa, acaba alterando o seu objetivo principal, já que a "essência de sua existência" deixa de ser a prestação de serviço educacional de qualidade para a obtenção de lucro por parte dos investidores.

Todas as mudanças sociais, políticas, econômicas e culturais afetam, de alguma forma, os sistemas educacionais (LIBÂNEO, 2000) e impactam diretamente no trabalho do docente, que é aquele que lida diretamente com os alunos. São eles que sentem os impactos da massificação do ensino, das salas cheias e dos alunos heterogêneos que adentram o ambiente acadêmico (ESPEJO; PREVIDELLI, 2005). Portanto, este estudo se volta para esses sujeitos de pesquisa, que têm seu trabalho precarizado e intensificado em face dos fatos apresentados.

Assim, com as novas tendências educacionais e mercadológicas descritas advindas da empresarialização das instituições educacionais (DEMO, 2007), que são geridas pela pressão

ReFAE - Revista da Faculdade de Administração e Economia, v. 8, n. 2, p. 60-86, 2017 
do mercado e em que o poder de decisão do docente é transferido para os administradores de metas, indaga-se: qual é a percepção dos docentes do ensino superior privado sobre sua vida profissional, com a crescente mercantilização das instituições educacionais?

Como objetivo central, este artigo procura caracterizar a vida profissional do docente do ensino superior privado, com base em sua própria percepção sobre seu trabalho. Para isso, foi tecida, no referencial teórico, uma evolução história sobre as mudanças nas formas de trabalho, além de uma contextualização sobre o trabalho do professor do ensino superior privado no que se refere às suas vivências dentro das instituições. Em um segundo momento, realizou-se uma pesquisa qualitativa com seis docentes, por meio do método Histórias de Vida.

\section{REFERENCIAL TEÓRICO}

\subsection{A Crise do Fordismo}

Para que seja possível assimilar todas as transformações ocorridas no trabalho nas últimas décadas, é preciso, antes de tudo, perceber o contexto em que se insere o trabalho por todo o mundo (BENDASSOLLI, 2007). As relações trabalhistas têm sofrido mudanças desde o final do século XIX (DAHL, 2001), momento em que o capitalismo passou por um período de mudanças e adaptações, o que, na visão de Boltanski e Chapello (2009), irrigaram novas formas de organização do trabalho.

Até os anos 60 do século XX, a competitividade baseava-se em grandes produções seriadas a baixo custo o que significava uma produção em massa para um consumo padronizado (CORIAT, 1995). O modo de produção hegemônico da época, o fordismo, iniciou-se em 1914, ano em que Henry Ford introduziu a recompensa de cinco dólares para os trabalhadores da linha de montagem de veículos, por oito horas de trabalho (HARVEY, 2005). Suas ideias somaram-se às ideias de Frederick Taylor, já em curso desde o final do século XIX, adicionando-se a elas o uso de inovações tecnológicas e organizacionais (SANTANA, 2005), como a linha de montagem, que acabou tornando-se uma tendência da época pela rapidez da produção (HARVEY, 2005). Esse trabalho mecanizado dispensava a autonomia laboral e a criatividade, o que fez surgir contestações que originaram mudanças nas relações de trabalho. As insatisfações surgiram tanto da "crítica social", que se refere às exigências de garantias trabalhistas; quanto da "crítica estética", que está relacionada à exigência de autonomia e liberdade no trabalho. (BOLTANSKI; CHIAPELLO, 2009).

ReFAE - Revista da Faculdade de Administração e Economia, v. 8, n. 2, p. 60-86, 2017 
Essas insatisfações fomentaram ações por parte dos trabalhadores para que houvesse mudanças nas formas de trabalho. Houve manifestações dentro e fora das organizações, que incluíam greves, operação tartaruga, boicote e sabotagens (PASTRE, 1983). Ainda na década de 60, outros acontecimentos cooperavam para que o fordismo perdesse sua força. A Europa Ocidental e o Japão, por exemplo, se viam com seus mercados internos saturados, o que significava a necessidade de exportação. Consequentemente, os Estados Unidos viam sua demanda enfraquecer, originando uma guerra por mercados, já que vários países recém industrializados desafiavam a sua hegemonia. Houve, então, o movimento de multinacionais para solos ode os contratos de trabalho eram mais fracos ou inexistentes, para garantir melhores preços de produção (HARVEY, 2005). Havia ainda os impactos da crise do petróleo na economia, que culminaram em crise energética que encareceu a produção e diminuiu os lucros.

Fora das paredes organizacionais, em maio de 1968, na França, houve uma greve geral com a participação de trabalhadores e estudantes. Segundo sociólogos e especialistas, a base da revolta não era a busca por garantias trabalhistas; pelo contrário, tratava-se muito mais de uma crítica aos trabalhos nas linhas de montagens, ou seja, era uma revolta contra o fordismo. E como havia naquele momento a elevação da escolarização dos jovens, causada pela explosão universitária da época, os trabalhos não eram mais compatíveis com o perfil desses jovens, que demandavam empregos em que pudessem usar sua criatividade e autonomia. Assim, eles começaram a recusar trabalhos, preferindo, por vezes, serem marginalizados a contribuírem com o capital tal e qual ele se mostrava (BOLTANSKI; CHIAPELLO, 2009).

Ainda segundo os autores, nesse novo contexto, a gestão autoritária até então em vigor tornou-se obsoleta. Passou-se a demandar a substituição de grupos autoritários por grupos semiautônomos, devendo os gerentes preocupar-se em ser mais conselheiros e norteadores do trabalho, em vez de ditadores.

\subsection{A Terceira revolução Industrial e a Emergência de Novas Configurações de}

\section{Trabalho}

Para compreender a terceira revolução industrial é preciso reconhecer que ela foi além de um "fetiche tecnológico". É fato que, com esse movimento, recursos tecnológicos importantes tenham tomado forma, como a ampliação da comunicação em tempo real, possibilitada pela internet, bem como avanços permitidos pelo desenvolvimento da microtecnologia. No entanto, a mudança tecnológica, ocorrida desde o período pós-guerra,

ReFAE - Revista da Faculdade de Administração e Economia, v. 8, n. 2, p. 60-86, 2017 
aliada às transformações que ocorriam na França, resultou em uma nova forma de organização do trabalho, que alterou o processo produtivo. Esse contexto impactou na “divisão do trabalho, no mercado de trabalho, no papel dos sindicatos e nas negociações coletivas", desconstruindo o mundo do trabalho como se conhecia. Tratou-se, portanto, de um processo econômico, político e cultural dinâmico, "em escala planetária”. (SILVA; SILVA; GOMES, 2002, p.04).

Como visto na seção anterior, as medidas que propiciavam garantias aos empregados foram substituídas por outras que suavizavam o controle hierárquico. Assim, ao invés de se pensar no trabalhador de forma coletiva, passou-se a considerar seus potenciais individualmente. Desse modo, as garantias foram trocadas pela autonomia, com uma hierarquia menos direta. E foi justamente pela concessão de autonomia aos empregados que as empresas voltaram ao controle organizacional, já que o autocontrole passou a imperar. Bendassolli (2007, p.12) expõe, que o autocontrole se fundamentou pelas novas formas de gerenciamento que passaram a ocorrer com intensiva utilização de novas tecnologias.

O trabalho teve um enriquecimento de tarefas e os horários tornaram-se flexíveis o que atraiu a mão de obra que há muito ansiava por trabalhos menos mecânicos. A flexibilização do trabalho tornou-se, então, uma nova tendência. Diversas outras mudanças favoreciam a flexibilização do trabalho, como: modificações nos módulos de montagens, terceirização, criação de grupos de trabalhos flexibilização do horário, criação de trabalho parcial, escalonamento de férias e planejamento do fim da carreira (PASTRE, 1983).

Muitas dessas novas formas de trabalho contribuem para a precarização, como no caso da terceirização, com suas relações de subcontratações, que têm se tornado comuns, principalmente pelo aumento do setor de serviços. As áreas que tendem a ser terceirizadas são: serviços de limpeza, segurança, lavagem de roupa, alimentação, transporte dentre outras (BOLTANSKI; CHIAPELLO, 2009). Sobre a terceirização, Franco, Druck e Seligmann-Silva (2010) afirmam que ela, juntamente com a desregulamentação social, produziu a desestabilização do mundo do trabalho, que atingiu inicialmente os trabalhadores industriais e depois todos os assalariados, afetando hoje todos os que vivem do trabalho.

É importante mencionar ainda que, com o advento da tecnologia, as relações profissionais e pessoais mudaram. O controle passou a extrapolar os muros institucionais e as paredes organizacionais por meio da comunicação instantânea, possível graças à mobilidade dos meios de comunicação e às novas formas de socialização advindas de um aparato comunicacional interconectado (FOUCAULT, 1987). 
Assim, as mudanças, mesmo tão profundas, ocorreram com o aval da sociedade, ou seja, sem revolução ou golpe de Estado, mas sem debates abertos que analisassem a grandiosidade das modificações que ocorriam no trabalho. As mudanças foram rotuladas pela flexibilidade - palavra de ordem da época (BOLTANSKI; CHIAPELLO, 2009). Diante disso, compreende-se que se iniciou uma era de trabalho flexibilizado, que teve suas garantias reduzidas e menor apoio dos sindicatos, em nome da maior autonomia no ambiente organizacional.

\subsection{Precarização, Intensificação e Reflexo dos Sistemas de Gerenciamento Informatizados no Trabalho Docente}

Mendonça Neto, Antunes e Vieira (2012) afirmam que o Estado tem visto nas privatizações uma opção de parceria viável para atender ao cidadão em determinadas áreas em que, sozinho, o Estado não mais consegue. Desse modo, tem sido possível perceber, no Brasil, o robusto crescimento do ensino superior privado nos últimos anos, porém à custa de muitas modificações na rotina do trabalho do docente (BOSI, 2007). Com um maior número de alunos interessados em um curso de graduação, as IES criaram estratégias para se destacarem em um mercado cada vez mais competitivo (FREITAS, 2006).

Algumas táticas para o aumento de lucros vêm ocorrendo por meio da reestruturação operacional das instituições educacionais. Unidades de grande porte vêm adquirindo outras de pequeno ou médio pelas fusões de capital, o que tem originado instituições gigantes no ramo educacional. Essa cooperação permite grandes ganhos e maior visibilidade no mercado, bem como "novos nichos de mercado geográficos e vantagens pelo crescimento do número de alunos e de cursos já autorizados pelo MEC" (CARVALHO, 2013, p. 768).

Freire (1986, p.23) aponta que todo planejamento educacional, para qualquer sociedade, responde às marcas e aos valores desta. Ele acrescenta que o processo educativo funciona "ora como força estabilizadora, ora como fator de mudança. Às vezes, preservando determinadas formas de cultura; outras, interferindo no processo histórico instrumental". Assim, em um momento de mudança econômica, a escola sempre procurou atender às demandas por mão de obra para o desenvolvimento capitalista. Isso quer dizer que, em determinados momentos da história, a escola foi destituída de qualquer conteúdo político (OLIVEIRA; GONÇALVES; MELO; FARDIN, 2010), passando a cultuar a eficiência em detrimento da formação crítica. 
Em meio à mercantilização da educação, encontra-se o professor, que vê seu trabalho transformado. Hargreaves (1998) salienta que a maior fonte de intensificação no trabalho docente não estaria no trabalho prescrito, mas no trabalho real, uma vez que o foco de intensificação seria a auto intensificação, realizada pelos próprios docentes, que se envolvem afetivamente com o seu trabalho em uma escala maior que qualquer outro trabalhador.

Essa intensificação está diretamente relacionada à precarização que também se relaciona ao tratamento dispensado ao professor pelas Instituições de ensino superior. Entre 1984 e 2004, o aumento do número de docentes em instituições públicas foi de 53 por cento, enquanto nas instituições privadas esse aumento foi de 270 por cento (BOSI, 2007). O Censo da Educação Superior, realizado pelo INEP - Instituto Nacional de Estudos e Pesquisa (2012), registrou 217.834 docentes vinculados às IES privadas. Desses, apenas 25\% eram contratados por tempo integral; outros $31,2 \%$ por tempo parcial, enquanto $43,8 \%$ eram professores horistas. As formas de contratação mencionadas deixam o trabalhador inseguro quanto ao seu trabalho e seus ganhos pela incerteza do número de aulas que terá no semestre seguinte, o que impacta em sua vida como um todo, incluindo seus planos de aquisições de bens. É a " precarização do trabalho docente expresso nas novas e velhas formas de contratação" (BOSI, 2007, p.1511). A precarização do trabalho tem implicações também de caráter social, cultural e político (BOSI, 2011), já que existe a desvalorização social do papel do professor.

Martins e Honório (2012) afirmam que em uma pesquisa com a participação de 600 docentes em um centro universitário de Belo Horizonte, adquirido por um grupo empresarial de São Paulo, constatou-se que a competitividade do setor aumentou ao mesmo tempo em que a autonomia dos professores diminuiu. Essa realidade gera sobrecarga e estresse, que precariza o trabalho dos docentes. Vale ressaltar que os alunos se encontram dispersos, desinteressados ou menos interessados que antes, mais superficiais, mais indisciplinados, assumindo uma postura de "aluno-cliente", aceita pelas IES (SENO; KAPPEL; VALADÃO JÚNIOR, 2014).

Assim, nas últimas décadas, as organizações educacionais vêm adquirindo características semelhantes às encontradas em outras organizações produtivas (BOSI, 2011). Tumolo e Fontana (2008, p.07) acrescentam que o trabalho produtivo se faz presente em toda e qualquer relação de produção capitalista contemporânea. Não faz diferença se "trata-se de uma empresa agrícola, fabril ou de uma escola; se a mercadoria produzida é soja, robô ou ensino". Eles salientam ainda que existe a "conversão dos professores em proletários ". Os 
autores explanam que ser proletário significa não ter autonomia no que se realiza, além de viver de salário, alienando a força de trabalho. Nesse sentido, os autores fazem a associação do trabalho docente com o das fábricas, por gradativamente incorporar características do modo de produção fabril como o taylorismo, que envolve a repetição, a padronização e a fragmentação.

Somadas à auto intensificação, às formas de contratação precárias e às novas tendências que colocam o aluno como um "cliente", mais que como um estudante em processo de aprendizagem, estão as demandas impostas pelas instituições de ensino superior, como as atividades que requerem preenchimento de relatórios, lançamento de frequência e conceitos online, atividades pelas quais o professor não recebe e que não estão incluídas em seu regime ou carga horária de trabalho (GUIMARÃES et al., 2012), além da produção e postagem de materiais didáticos em sistemas eletrônicos, e outras atividades extras (OLIVEIRA, 2006). Tudo com prazo pré-determinado (SILVA JÚNIOR; SGUISSARDI; PINTO e SILVA, 2010). A informatização, portanto, coopera para a intensificação do trabalho docente. Percebe-se que os professores têm estado sob ampla "vigilância, controle e adestramento", devido às novas formas gerencialistas de gestão em que se encontram as instituições de ensino (MENDONÇA NETO, ANTUNES E VIEIRA, 2012, p. 02).

Os sistemas voltados à gestão educacional se enquadram como partes do dispositivo de controle, vigilância e adestramento das atividades do professorado. Essa vigilância pode atuar tanto como uma ferramenta pedagógica, quanto como uma ferramenta criada para restringir a liberdade do docente ao executar suas atividades cotidianas (SEWELL; WILKINSON, 1992).

O adestramento, foi um termo utilizado por Mendonça Neto, Antunes e Vieira (2015). Segundo os autores, o termo pode ser utilizado dentro do contexto das ideias de Foucault (1987), já que nos cavalos, o adestramento produz efeito de harmonia física para que o animal adquira determinadas habilidades. O resultado é um cavalo mais manso e dócil, além de confiante, atento e interessado, submetendo-se ao controle do governante. O trabalho, portanto, pode e é, por vezes, utilizado como adestramento do sujeito, para que haja o controle sobre seu trabalho.

Best (2010) menciona que existe uma grande facilidade de coleta de dados pela tecnologia digital atual, que contribui em grande escala para o exercício do controle dos docentes. Com isso, fica fácil identificar os sujeitos que se encontram fora dos padrões exigidos pelas instituições e aplicar sanções para que eles se convertam em docentes mais 
dóceis, que se adaptem às exigências institucionais. Além de todos esses dispositivos, a gestão das instituições frequentemente marca encontros ou reuniões que não têm um caráter pedagógico, mas que informam aos docentes sobre os padrões de comportamento deles esperados para o andamento das atividades. Tais dispositivos têm apenas a função de adestramento docente, não se caracterizando em nenhum aspecto como atividade pedagógica (MENDONÇA NETO; ANTUNES; VIEIRA, 2012).

Therrien e Carvalho (2009, p.36) afirmam que submeter um professor a dispositivos como os mencionados ao longo desta seção implica colocá-lo em um "dirigismo", uma espécie de piloto automático, que desvaloriza sua prática, prejudicando sua atividade intelectual ao subordiná-lo aos dispositivos de vigilância por todo o tempo, na tentativa de adestrá-lo a um sistema de metas. É a mais nova forma de precarização de trabalho docente, que faz com que o professor perca parcialmente seu senso de criatividade e inovação.

Em suma, o cenário de controle emergente destaca a ideia de cada um vigiar a si mesmo, avaliando-se conforme critérios alheios, sem a presença constante de um superior. Assim, não existe uma forma de controlar aquilo que é incontrolável, como a criatividade, a autonomia ou até mesmo a iniciativa alheia, a não ser fazendo com que as equipes controlem a si mesmas. Ou seja, há a passagem do controle para o autocontrole também nas instituições de ensino, já que a ascensão profissional de cada um dentro de uma instituição dependerá do grau de envolvimento do trabalhador com suas atividades profissionais (ARAUJO, 2006).

\section{METODOLOGIA}

Este estudo se deu por meio de um estudo descritivo, de natureza qualitativa, pelo método Histórias de Vida. Esse método é importante porque existe, nessas histórias, uma contextualização não apenas pessoal, mas também histórica, social, institucional e/ou política e, por meio delas, revelam-se ações e emoções (XING; SIMS, 2012), dos sujeitos de pesquisa, sendo necessário, para compreendê-las, adentrar o universo do informante, buscando uma análise grupal, cultural, ideológica e histórica, já que as experiências pessoais derivam desse contexto (DENZIN, 1989).

No caso deste estudo, os sujeitos de pesquisa foram os professores atuantes em instituições de ensino superior privadas pertencentes a grandes grupos educacionais de Belo Horizonte, Minas Gerais. Conforme sugerido por Queiroz (1991), definiu-se os sujeitos de pesquisa segundo os traços preponderantes que ligam as suas trajetórias aos objetivos da pesquisa. O número de professores foi definido segundo critério de saturação de dados. 
Fontanella, Ricas e Turato (2008) explicam que esse método é utilizado para estabelecer ou fechar o tamanho final de uma amostra em estudo, interrompendo a captação de novos componentes. Assim, encerrou-se a pesquisa com seis narrativas individuais. Dos seis docentes, um trabalha somente no grupo Splice (Newton Paiva); dois trabalham somente no grupo Kroton, porém, cada um trabalha em uma marca diferente do grupo e, por terem ambos passaram pelo processo de fusão em 2014, trazem percepções relevantes sobre suas vivências; e três docentes trabalham, ao mesmo tempo em duas ou mais instituições, como Kroton, Estácio, Anima e outras faculdades menores, o que constituiu importante e rica fonte de dados pelas diferentes percepções vindas das vivências dos docentes nas instituições onde lecionam.

A coleta de dados foi realizada por entrevista narrativa, em encontros individuais em que os docentes foram convidados a falar livremente sobre sua trajetória de vida, conforme sugerido por Denzin (1989) e em determinado momento, foi pedido que eles focassem em sua trajetória profissional enquanto docentes do ensino superior privado de grandes grupos educacionais. As falas foram transcritas e, em seguida, conforme sugerido por Mageste e Lopes (2007), foi feita a escuta do depoimento simultaneamente à leitura do documento. Uma síntese dos relatos foi escrita e apresentada antes das análises interpretativas, conforme proposto por Closs e Antonello (2011).

Para a análise dos relatos, utilizou-se a análise de conteúdo. Bardin (1979) define a análise de conteúdo como um grupo de técnicas para análise de comunicações que visam à obtenção de descrição do conteúdo de mensagens e indicadores que permitam a inferência de conhecimentos referentes à produção ou recepção dessas mensagens. Assim, para que fosse possível realizar a análise de conteúdo, as entrevistas gravadas foram transcritas; em seguida, separadas segundo as categorias e subcategorias emergentes.

\section{SÍNTESE DOS RELATOS}

Os sujeitos de pesquisa deste estudo receberam nomes fictícios para preservação de sua identidade. Os nomes das instituições por onde passaram também foram preservados. A seguir, apresentam-se as sínteses de seus relatos.

\subsection{Relatos de André}

André é um professor de 43 anos graduado em História e em Engenharia de Produção, mestre em Educação, doutorando em Engenharia Ambiental e, atualmente, professor assistente de uma universidade federal. Ele leciona em cursos de Engenharia. 
Sua carreira começou na indústria como técnico em segurança do trabalho. O docente conta que a vida na indústria o levou para a academia; o motivo é que dentro da indústria ele era levado a dar treinamentos, o que o aproximou do universo do ensino e o fez querer estudar além de seu curso técnico inicial de Técnico em Segurança do Trabalho. Entrou para a universidade, fez um curso de história para conseguir compreender a sociologia do trabalho e, em seguida, iniciou o mestrado. Teve uma vivencia de cinco anos em um grande grupo educacional brasileiro e relatou, com pormenores, diversas situações que ele caracteriza como "incoerentes" com o que a educação representa.

\subsection{Relatos de Pablo}

Pablo é um professor de ensino superior, solteiro, de 38 anos, com duas graduações: em História e em Gestão de Recursos Humanos. O docente é pós-graduado em História da Política e Gestão de Pessoas. Cursa mestrado em Administração e leciona nos cursos tecnólogos de Gestão de Recursos Humanos, Marketing, Logística e no curso de Administração.

O docente iniciou sua carreira trabalhando na área administrativa de uma faculdade privada. Ele teve também uma experiência como docente ao trabalhar em uma escola regular como professor de história, experiência que o fez querer maiores desafios na área de ensino. Com o tempo e com muito estudo e dedicação, aos 29 anos, conseguiu passar do administrativo para a docência na mesma instituição onde trabalha até os dias atuais. Recentemente, a instituição foi adquirida por um grande grupo educacional brasileiro e essa aquisição propiciou grandes mudanças em sua forma de trabalho. Pablo relatou, detalhadamente, tudo o que vivencia no cotidiano da instituição.

\subsection{Relatos de Rodrigo}

Rodrigo é um docente de 56 anos de idade, solteiro, com grande experiência em diferentes instituições de ensino superior. Ele é graduado em Psicologia, possui pósgraduação em Administração de Recursos Humanos e é mestre em Administração de Empresas. Ele leciona nos cursos de Administração, Ciências Contábeis, e nos Curso Tecnólogo de Recursos Humanos.

Sua carreira teve início em 1994, em uma escola de curso técnico em Administração em São Paulo. O docente relata que essa foi uma das experiências mais gratificantes de sua carreira, pela grande bagagem de aprendizagem que adquiriu e pelas relações humanas que

ReFAE - Revista da Faculdade de Administração e Economia, v. 8, n. 2, p. 60-86, 2017 
foram duradouras e muito significativas. Sua passagem por cursos técnicos perdurou até 2002, quando entrou para instituições de ensino superior. Sua experiência em cursos de ensino superior inclui diversas faculdades privadas em São Paulo e Minas Gerais, o que dá ao docente uma boa base para traçar comparações entre o modo de lecionar entre elas. Hoje o docente leciona em duas faculdades. Uma delas pertence a um grande grupo educacional, enquanto a outra é de porte menor. Seus relatos mostram a diferença que existe em lecionar nas duas instituições e retratam o universo em que seu trabalho se insere.

\subsection{Relatos de Bruno}

Bruno é psicólogo e docente do ensino superior privado. Ele tem 36 anos e sua formação é em Psicologia, licenciatura e bacharelado. Sua pós-graduação é na área de Psicologia Clínica e ele cursa o mestrado. Sua experiência no ensino superior iniciou-se em 2008, embora ele esteja na instituição desde quando era aluno, o que soma 16 anos dentro da faculdade. O docente leciona no curso de Psicologia.

Ele relata que, logo que se formou, teve a opção de se mudar para o interior para trabalhar apenas com a parte clínica, ou continuar desenvolvendo projetos dentro da instituição onde se formara, uma vez que havia participado do processo seletivo e já havia sido aprovado. Como ele planejava iniciar a docência logo que possível, optou por permanecer em Belo Horizonte e desenvolver-se academicamente e também na prática clínica para ministrar aulas para o ensino superior de forma a conseguir dar boas contribuições tanto teóricas quanto práticas aos alunos. Seu plano funcionou e, em 2008, começou a dar aulas na instituição. Pouco tempo depois que ele entrou na instituição como funcionário, ela foi comprada por um grande grupo educacional, assunto sobre o qual ele relata suas experiências. Bruno trabalha em regime integral e conta como é trabalhar com esse regime na instituição privada onde leciona.

\subsection{Relatos de Sofia}

Sofia é professora do ensino superior privado viúva, de 44 anos. Sua formação é em Psicologia, ela é especialista em Gestão de Pessoas e mestre em Gestão Social, Educação e Desenvolvimento local. Sua experiência no ensino superior envolve três faculdades privadas na cidade de Belo Horizonte, Minas Gerais. Ela leciona, atualmente, nas disciplinas da área de humanas nos cursos de Engenharia e no curso Tecnólogo em Recursos Humanos. 
A professora relata que sua trajetória profissional teve início com psicologia clínica e, em seguida, psicologia organizacional em uma instituição pública, e depois, privada, por nove anos. Posteriormente ela trabalhou com Recursos Humanos na área de Recrutamento e Seleção e principalmente Treinamento e Desenvolvimento que era uma área muito parecida com a docência, na visão da docente. Como Sofia queria ser professora desde criança, almejou desde o princípio a oportunidade de atuar no ensino superior e, em 2008, começou a atuar na área que queria. Ela começou sua carreira como docente na mesma instituição em que tinha, anteriormente, um cargo na área de Recursos Humanos. Trata-se de um grande grupo educacional. Em seguida, a docente teve outra experiência em uma faculdade menor, que não durou muito tempo. Na sequência, ela começou a trabalhar em outro grande grupo educacional. Sofia detalha, em sua história, as diferenças e as semelhanças existentes em se trabalhar nas instituições onde lecionou.

\subsection{Relatos de Carmem}

Carmem é uma profissional de 42 anos, casada, graduada em Pedagogia, pós-graduada em Gestão Estratégica de Negócios e também em Gestão de Pessoas. Além disso, é mestre em Comunicação e Tecnologias Educativas. Ela formação internacional, na área de coaching $e$ é analista do comportamento humano. Embora Carmem atue no mercado financeiro há quase 20 anos, sua experiência como docente no ensino superior privado começou em 2010. Ela leciona nos cursos de Administração, Ciências Contábeis e Tecnólogo em Recursos Humanos.

A primeira faculdade onde lecionou era "pequenininha", como a docente define. Ela conta que entrou como professora substituta, mas foi muito reconhecida pelos alunos que pediram que ela continuasse mesmo após a volta da professora. Sua segunda experiência, foi em uma faculdade maior. Nessa instituição, Carmem conta que começaram, além dos prazeres da profissão, alguns desconfortos, que ela não havia percebido no lugar onde lecionara anteriormente. Ela aponta que a instituição, embora seja parte de um grande grupo educacional, precisa se desenvolver muito no que tange ao olhar sobre o trabalho docente. A professora continua seus relatos revelando algumas percepções sobre o seu trabalho.

\section{APRESENTAÇÃO E ANÁLISE DOS RESULTADOS}

Durante a coleta dos relatos, algumas categorias emergiram de forma natural aos sujeitos de pesquisa. Essas categorias foram: a intensificação dos esforços docentes; a 
precarização do trabalho; e o impacto de sistemas informatizados de gerenciamento na vida do professor. A seguir, algumas análises serão feitas sobre cada uma dessas categorias.

\subsection{A Intensificação dos Esforços Docentes}

Para iniciar as análises quanto à intensificação dos esforços do trabalho docente, é relevante lembrar as palavras de Hargreaves (1998) quanto à auto intensificação presente no trabalho do professor. $\mathrm{O}$ autor expõe que esse fator leva o profissional da educação a se envolver com seu trabalho, mais que outros profissionais. Assim, ao que lhe é cobrado diariamente pelas instituições, o docente adiciona a auto cobrança, que faz com que seu trabalho seja ainda mais intenso e mais pesado. A auto intensificação foi captada no relato de todos os docentes, conforme ilustrado a seguir:

(...) Eu me preocupo, não é chegar na sala e jogar conteúdo. É importante que o aluno saiba fazer conexões, que ele entenda onde ele vai usar e qual a importância daquele conteúdo, eu me cobro isso (Sofia).

Na universidade existe uma relação do aluno com o professor, que deveria ser muito mais de afetividade e aprendizagem. Essa relação não pode se misturar com a parte técnica da instituição. A gente tem que fazer com que o aluno aprenda o máximo, esse é o meu papel (...) (Rodrigo).

Assim, Sofia e Rodrigo mostram as nuances do trabalho de um professor. Eles mostram o quanto se cobram para que o trabalho seja bem feito em prol do desenvolvimento dos discentes. Na mesma linha, Pablo e Bruno, em suas considerações sobre o assunto, relatam que a sua própria preocupação com seu alunado é maior que a preocupação da instituição para com a aprendizagem dos discentes. Eles assumem que se sentem na obrigação de dar ao aluno aquilo que, às vezes, nem o próprio discente valoriza tanto. Utilizando-se de palavras diferentes, ambos expõem a ideia de que a instituição quer ter o aluno, e o aluno quer ter o diploma e o professor, nesse contexto, se torna um dificultador do processo.

Este artigo trouxe a ideia de Seno; Kappel e Valadão Júnior, (2014) quanto ao alunocliente, que possui um perfil indisciplinado e desinteressado, como quem escolhe a instituição seduzido pelo preço, indiferentemente da qualidade de ensino prestada. Tratar o aluno como cliente exige esforços por parte do professor, que, por sua vez, precisa mudar sua forma de ensinar, focando em agradar o "cliente" para que este não desista do curso. Assim, as metas são alcançadas, como requer a diretoria. 
(...) eles são mais clientes que alunos. Quando um coordenador precisa de meta, ele não pode deixar o cliente ir embora. Aí ele começa a chamar o professor e pede para ele diminuir [o ritmo] (Pablo).

(...) eu não tenho que agradar a faculdade ou os coordenadores, eu tenho que agradar os meus alunos. Acredito que muitos colegas não gostam dessa frase, mas eu trato meus alunos como meus clientes. Porque sem aluno não tem faculdade, não tem ensino, não tem salário, não tem nada(...) (Carmem).

Para compreender a divergência de pensamento entre Carmem e Pablo, é relevante levar em consideração o perfil de cada um. Pablo é professor horista com licenciatura e não exerce outra atividade remunerada. Em contrapartida, Carmem atua no mercado financeiro durante o dia e dá aulas alguns dias durante a noite. Ela afirma compreender a questão financeira das instituições por trabalhar movida por metas no outro emprego. Trata-se, então, de uma situação familiar a ela, que vive em um contexto mercadológico. Já o professor, que é acadêmico, não enxerga a educação dentro de um contexto de mercado, sujeito à competitividade e oscilações.

Nessa linha, as ideias de Tumolo e Fontana (2008) apontam que o processo de ensino/aprendizagem tem sido tratado como qualquer outro modelo produtivo, o que transforma os docentes em "proletários", sem autonomia e sem controle quanto à tarefa a executar. Os docentes parecem ter consciência disso. Como exemplo, André afirma que:

(...) eles mandam os modelos de aula. (...) tem que dar aquele conteúdo estipulado. Sobre o ponto de vista da organização parece muito mais fácil, é a ideia taylorista da organização de trabalho. Qualquer um pode executar. (André).

(...) quanto mais você ministra aulas, mais coisa você tem que fazer. Já chegou em um ponto de eu pensar em rever a minha permanência, ou a quantidade de aulas que eu dou. De cada manual que me entregam, eu tenho que fazer quase 500 slides. Se eu dou 5 disciplinas, eu terei então que fazer 2500 slides, e em pouco tempo. (Rodrigo)

Esse processo, chamado por André de taylorização, pode parecer simplificar o processo de ensino para o professor, já que a instituição lhe fornece prontamente o material a ser lecionado. No entanto, os docentes que já vivenciaram essa rotina afirmam que a aulamodelo das instituições aumenta a exigência da preparação, já que os docentes passam a trabalhar com materiais que não conhecem e às vezes nem sequer aprovam. Assim, ao invés de conduzirem a aula com prazer, acabam se frustrando. Rodrigo é muito enfático quando propõe que:

(...) uma disciplina é ministrada para o Brasil inteiro! E o grande erro é esse. Você

vai dar Psicologia para Administração e a grade é voltada para história da

ReFAE - Revista da Faculdade de Administração e Economia, v. 8, n. 2, p. 60-86, 2017 
psicologia. Nada para o administrador. Não fala de motivação, liderança, relacionamento interpessoal. E daí entra o professor e adapta. Mas quando eles tentam padronizar, aí não dá mais para adaptar. Tem que repensar isso. (Rodrigo)

Todos os sujeitos de pesquisa deste estudo relataram que além das atividades cotidianas inerentes à atividade docente, como correções de avaliações, elaboração de provas, dentre tantas outras, há ainda atividades constantes que geram grande demanda de trabalho, sem retorno financeiro algum. Pablo ilustra a situação com o relato a seguir:

(...) meu nome ia para todas as comissões dentro da faculdade. Se tem que reconhecer curso, se tem CPA, se tem que receber alguma diretoria, o meu nome está lá, e isso, gera um trabalho extraclasse inacreditável! E sem retorno financeiro. (Pablo)

Então marca-se a reunião e se no dia você estiver, você participa, mas se você não estiver, você não é obrigado a vir. Mas não vir é algo complicado, então tem isso, entendeu? E a gente não recebe nada, hora extra, nada (Bruno).

Assim, percebe-se que os encontros marcados pela coordenação são momentos que desgastam o professor e acabam gerando um paradoxo em sua vida: se ele for à reunião, perde um tempo que seria importante para descanso, preparação de aulas ou estudos. Mas se não for, ficará mal visto aos olhos dos coordenadores. Diante disso, muitos optam por comparecerem, embora sintam-se injustiçados e acuados. Todo esse contexto reforça a ideia de Oliveira (2006) sobre a ideia da intensificação do trabalho por meio de atividades extras.

Outro ponto que aumenta os esforços por parte do professor é o excesso de alunos em sala de aula, como destacado por Carvalho (2013) no decorrer deste estudo. Esse aumento de alunos por sala advém do crescimento do ensino superior privado nos últimos anos em virtude de concessões de bolsas pelo governo que alavancaram a empresarialização do ensino.

Eu peguei uma turma que tinha 160 alunos. Quando você dá um trabalho, você tem que corrigir, você leva para casa 160 trabalhos ou projetos (...).Esse é um ponto em que o professor sofre com as decisões tomadas pela instituição (Carmem).

Eles juntam as salas! Em vez de ter turmas de $1^{\circ}, 2^{\circ}, 3^{\circ}$ e $4^{o}$, você tem um bloco de disciplinas em que jogam alunos de todos os cursos para diminuir o custo (Pablo).

Assim, todas as vivências relatadas acima mostram o caráter de urgência em se lançar um novo olhar para o professor. Os relatos deste estudo demonstraram que os docentes têm sentido o impacto da empresarialização das instituições de ensino, que querem continuar gerando lucros em detrimento de um ensino de qualidade e do bem-estar de seu corpo docente. 


\subsection{Precarização do Trabalho Docente}

A palavra precário, segundo Ferreira (2010), pode ser compreendida como aquilo que é difícil, minguado, ou mesmo escasso insuficiente, incerto, contingente. Pode ser ainda compreendido como pouco durável, débil ou delicado. Assim, compreende-se que o trabalho precário não está somente relacionado ao trabalho incerto ou instável, o que está ligado diretamente a impactos financeiros na vida do trabalhador; mas também à fragilização ou delicadeza da posição do trabalhador diante da organização onde atua.

Diante disso, o Inep (2012) retratou que a maioria dos docentes do ensino superior privado trabalha como horistas. Isso significa que recebem segundo número de aulas que ministram, e que seus salários estão constantemente em alteração. Dos seis professores entrevistados, cinco são horistas nas instituições privadas onde lecionam, enquanto apenas um trabalha em Regime Integral. É válido ressaltar que esse único docente aponta que em sua instituição há apenas dois professores contratados nesse modelo. Tanto os horistas quanto o professor de regime integral relatam experiências de precarização no trabalho.

Alguns dos docentes expõem, que recebem algumas horas para fazer trabalho de cunho administrativo, mas recebendo um valor inferior ao que um atendente administrativo ganharia. Eles salientam que se trata de uma estratégia das organizações para diminuir custos com pessoal. Demo (2007) salienta que as instituições são geridas pelas pressões de mercado. Assim, os cortes com pessoal aumentam os lucros institucionais. Um exemplo se dá a seguir:

\section{(...) uma coordenadora queria que eu estivesse na instituição praticamente todos os dias, mas recebendo por 4 horas, para poder atender aluno e ajudá-la a fazer outras coisas administrativas. Teve uma vez que eu falei que se eu fosse tão competente assim, que aumentasse a minha carga horária(...) (Pablo).}

Outra queixa bastante comum entre os docentes horistas é referente à instabilidade devido à carga horária, que muda a cada semestre. Sobre isso, Pablo afirma que suas horas oscilam consideravelmente, o que, em suas palavras, "impede o planejamento financeiro a médio e longo prazo". A situação exposta foi encontrada de forma similar nos relatos de quase todos os docentes, como no caso de Sofia abaixo:

Comecei com 16 horas-aula (...) depois passou para 8, no outro eu tinha 12. E só consegui durante 2 semestres ter 20h. Não posso fazer programação financeira para o semestre seguinte, já que eu não sei o número de aulas que eu vou lecionar (Sofia).

Assim, percebe-se que a docente se sente da mesma forma que Pablo: insegura quanto à estabilidade do emprego. Por causa disso, ela já precisou trabalhar na mesma noite, em duas 
instituições diferentes, na esperança de não ficar sem aulas. O resultado disso ela expõe a seguir:

(...) Eu saía lá de próximo ao centro, no meio do horário, em torno de 8 h30 da noite, e deslocava até a [outra instituição]. Só que isso é muito desgastante, deslocar na mesma noite para dois ambientes diferentes (Sofia).

Conforme descrito neste estudo, a precarização não está relacionada apenas às formas de contratação, nem somente à intensificação dos esforços, ou à fragilização das relações de trabalho, mas está também relacionada ao tratamento dispensado ao professor, o que defende Bosi (2007), já que essa precarização tem implicações de caráter social, cultural e político. Alguns docentes relataram casos em que houve descaso quanto às leis trabalhistas. Outros, exprimem situações de desrespeito ao docente. Sofia adverte que trabalhou sem carteira assinada em uma grande instituição por um ano, e foi demitida ao ser testemunho de um colega em um processo trabalhista contra a instituição. Pablo conta ainda que não recebe resilição de horas quando a instituição lhe dá carga horária menor que no ano anterior. Ele diz que entrar com algum processo trabalhista contra a instituição é perigoso, já que isso pode significar ficar sem trabalho devido às fusões e aquisições. Ele mostra sua insatisfação abaixo:

Os grupos que estão formando estão diminuindo a concorrência e aí, se você entra na justiça contra uma instituição, elas se comunicam e você não arranja mais trabalho em nenhuma. Você vai para a lista negra. Uma vez um diretor disse: o RH não pode desabonar um professor, mas eи posso... еи não sou RH (Pablo).

No entanto, ao contrário do que muitos docentes parecem supor, o regime integral de trabalho no ensino superior privado existe, embora seja em menor proporção, em conformidade com o que foi exposto pelos dados do Inep (2012). Todas essas estratégias propostas aos horistas ou não horistas, que precarizam seu trabalho, atestam as ideias de Baldan (2007), quando ele aponta que, por se tratar de uma competição predatória, barateia-se o custo para aumentar os ganhos e o poder de competitividade. A ideia está de acordo também com o que mostra o docente Bruno, no recorte abaixo:

(...) atualmente na [instituição] só tem eu e mais um somos Regime Integral no curso de Psicologia. Chegou até a 6 ou 8, quando eu entrei. Mas foram saindo, aposentando, pedindo licença, e eu continuei (Bruno).

Mesmo para os docentes que trabalham nesse regime, existe a precarização do trabalho, já que eles exercem atividades que somam além de 40 horas. Essa vivência, relatada por um docente, é certificada por Guimarães et al. (2012), quando ele expõe que o professor executa atividades pelas quais não recebe e que não estão incluídas em seu regime ou carga horária de trabalho. Essa situação pode ser ilustrada pela experiência de Bruno:

ReFAE - Revista da Faculdade de Administração e Economia, v. 8, n. 2, p. 60-86, 2017 
Sou regime Integral, 40 horas (...)houve uma mudança e nós estávamos sem coordenação até um mês atrás e eu assumi as funções por ser docente com 40h, já que estava há mais tempo na instituição e já conhecia os processos (Bruno).

Diante disso, percebe-se que ser docente em regime integral pode ser mais seguro em termos de salário e planejamento financeiro, mas não indica que há mais tranquilidade quanto às atividades executadas, afinal o docente ainda expôs que, por ser de Regime Integral, ficou no lugar da coordenação e fazia cerca de 60 horas, “(...) estava aqui todos os dias, todos os horários". Ou seja, sua posição continua fragilizada por se sentir coagido a agir da forma como a instituição dita para que não perca seu emprego.

\subsection{Sistemas informatizados de gerenciamento institucionais}

Neste estudo, foi possível perceber que o contexto de trabalho tem mudado em todas as esferas. Foi visto também que o trabalho docente está inserido nesse contexto de grandes mudanças. Todas essas alterações têm como pano de fundo a terceira revolução industrial, que contribuiu para que o mundo do trabalho se tornasse mais dinâmico, aumentando sua complexidade (SILVA; SILVA; GOMES, 2002), já que as pessoas passaram a fazer uso de diversos mecanismos eletrônicos tanto em sua vida pessoal, quanto em sua vida profissional.

Na visão de Mendonça et al. (2012), a informatização coopera para a intensificação do trabalho docente, vigiando-o e adestrando-os. Os docentes mostram, por meio de suas vivências, como isso ocorre no ensino superior. Como no caso de Pablo, a seguir:

(...) [os coordenadores] mandam mensagens sábados, domingos, feriados, manhãs, tardes, noites e madrugadas.. As informações migraram do e-mail para o whatsApp.

E você é obrigado a responder. Eu fiz uma reclamação formal com a diretoria e no final de semestre, queriam minha cabeça (Pablo).

Assim, Pablo expôs que as cobranças por meio dos dispositivos ocorrem a todo tempo, seja em dias de semana ou em dias de descanso, em horas apropriadas ou não. Isso faz com que ele se sinta controlado, já que alguns desses dispositivos que deveriam ser pessoais, como whatsapp, mostram se o professor leu ou não a mensagem, criando uma situação de extrema cobrança.

Bruno mostra que se sente da mesma forma, controlado pela instituição, que sabe se ele postou ou não o que deveria, ou se fez ou não a chamada do dia. Os exemplos dos docentes vão ao encontro do que afirma Best (2010) quando ele aponta que a tecnologia digital contribui grandemente para o controle dos docentes. Nesse aspecto, Bruno mostra que: 
Tem as chamadas, e o lançamento da aula(...). Se você não lança semanalmente, vem um e-mail com essa cobrança do setor específico (Bruno).

Percebe-se, então, que a vigilância e o controle chegam a causar desconforto nos docentes, já que funcionam tanto como ferramenta pedagógica quanto como uma ferramenta criada para restringir ou impedir a liberdade cotidiana do docente, na visão de Sewell e Wilkinson (1992). Pode-se visualizar essa situação no relato de Sofia, exposto a seguir:

Logo que eu entrei eu me sentia ok. Mas quando o novo sistema padronizado foi implantando, eu me sinto vigiada, policiada, monitorada. (...) eu elaboro um material que passa a ficar público para quem quiser utilizar. Não é justo. (Sofia).

Mendonça et al. (2012) salientam ainda que todos os dispositivos informatizados visam à redução de gastos, já que transferem para o docente as atividades que seriam do setor administrativo. No entanto os docentes argumentam que nem sempre conseguem fazer as plataformas disponíveis nas instituições funcionarem adequadamente para que seja possível fazer o que lhes é solicitado. O caso de Bruno exemplifica a situação:

Para faltas e lançamentos, nós temos um aplicativo no celular. E eu não consigo baixar esse aplicativo de jeito nenhum.. E wifi aqui na instituição não funciona, então a gente gasta pacote de dados do nosso bolso para fazer chamada (Bruno).

Therrien e Carvalho (2009, p.36) analisam que submeter um docente a dispositivos como os mencionados acima implica colocá-los em um "dirigismo", uma espécie de "piloto automático", desvalorizando sua prática e prejudicando sua atividade intelectual. Sofia relata que se sente desconfortável com os novos métodos e maneiras de lecionar, com o uso constante de tecnologias que engessam o trabalho docente e ilustra a ideia dos autores

Esse foi um semestre muito difícil. Teve inclusão de métodos diferentes que engessam o trabalho do professor. É um método que as aulas têm um determinado modelo, é uma aula padrão. Você acessa o sistema, essas aulas estão prontas (Sofia).

Às vezes, o trabalho docente é completamente substituído por plataformas digitais para a redução de custos. Nesse caso, o professor, que antes lecionava determinada disciplina, perde suas horas e, consequentemente, sofre uma redução em sua carga horária. Pablo faz algumas considerações a esse respeito:

(...) Reduzem o seu salário porque, com disciplinas virtuais eles estão simplesmente pagando a somente um professor sendo que pagariam a 50, ou até 100. E o menino paga normal. Já perdi muita aula para disciplina online. (Pablo)

Mendonça et al. (2012) apontam ainda que, às vezes, alguns desses sistemas de gerenciamento informatizados, como portais que marcam horário e tempo de conexão do 
docente, não têm função pedagógica alguma. Pelo contrário, têm a função de adestrar o docente para o cumprimento de planos e metas institucionais, por meio da definição de quem são os docentes que se encontram fora dos padrões.

Essas vivências ilustram a visão de Silva Junior, Sguissardi e Pinto e Silva (2010), quando registram que as demandas incluem preenchimentos de planilhas, formulários, planos de ensino, dentre outros materiais que apresentem com rigor e antecedência seus objetivos e estratégias de ensino. No entanto, os docentes apontam que até mesmo as próprias estratégias de ensino, que deveriam ser de escolha do docente, já são pré-definidas em algumas instituições.

Dessa forma, os discursos dos sujeitos de pesquisa apontam que a inclusão de plataformas digitais, bem como de dispositivos de controle do trabalho docente vêm contribuindo para que o trabalho dos professores sofra alterações em sua forma. No entanto, essa alteração nem sempre é positiva, por impactar na vida do docente de forma a reduzir sua carga horária, diminuir sua autonomia, fazê-lo ficar sempre alerta quanto ao recebimento de emails ou mensagens de seus coordenadores a qualquer tempo, assim como aos prazos para postagens de materiais e envio de provas para reprografia.

Assim, percebe-se que a tentativa é fazer com que o docente acredite que está participando do processo ou que sua vida está sendo facilitada pelos dispositivos, enquanto os relatos mostram que o que ocorre é o contrário. $\mathrm{O}$ uso excessivo das plataformas e dos dispositivos tem contribuído para a intensificação e engessamento do trabalho docente, tirando-lhe a criatividade e poder de decisão sobre suas aulas e estratégias.

\section{CONSIDERAÇÕES FINAIS}

Este estudo objetivou caracterizar a vida profissional de docentes do ensino superior privado que trabalham em instituições que são partes de grandes grupos educacionais, por meio do método Histórias de Vida, em que seis docentes foram convidados a falar sobre a sua trajetória. Buscou-se, por meio dos relatos, analisar suas vivências de intensificação dos esforços diante das demandas institucionais, a precarização laboral existente nessas instituições e o reflexo dos sistemas de gerenciamento informatizados na vida do profissional do ensino.

Os relatos mostraram que a gestão das instituições privatizadas coopera para que os docentes tenham seu trabalho intensificado e desvalorizado, levando-os a uma piora das condições laborais. Os motivos para a intensificação do trabalho docente incluem o excesso 
de alunos em sala de aula, provocado pela concessão de bolsas pelo governo; a auto intensificação; a preparação de aulas e correção de atividades para turmas grandes; além de ter a cobrança de tratar os alunos como clientes e fazer com que consigam boas notas no Exame Nacional de Desempenho dos Estudantes (ENADE) para a comprovação da qualidade de ensino da instituição. Os professores são cobrados e levados a elaborar exercícios e provas baseados nas avaliações do ENADE, o que, em sua visão, apenas treina o aluno para o teste, sem, necessariamente, aumentar o seu conhecimento.

Quanto à precarização do trabalho do professor, compreende-se que este se encontra em uma posição delicada e fragilizada frente às corporações que são gigantes no mercado educacional. Essa fragilização traz uma piora não apenas das condições de trabalho, mas também da renda dos docentes que têm seu trabalho pouco valorizado, mas que, mesmo assim, são muito cobrados no que tange a desempenho e resultados.

Ainda sobre a fragilização da figura do professor frente ao "mercado de ensino" um tópico importante abordado nos relatos foi o tratamento dispensado ao docente pelos coordenadores de curso, que carregam a pessoalidade para relações que deveriam ser profissionais. Segundo sua percepção, os coordenadores distribuem carga horária e fazem admissões e demissões levando em consideração fatores de cunho pessoal, e nem sempre as competências de cada professor. Os docentes relatam ainda o receio que sentem de, em algum tempo não haver opções de lugar para que possam trabalhar fora dos grupos, já que as faculdades menores acabam perdendo lugar para as maiores.

De modo geral, os docentes mostraram-se indignados com as modificações que vêm ocorrendo em seu cotidiano de trabalho. A maioria questiona sobre sua permanência na profissão e se posiciona como atores questionadores quanto aos novos processos que vêm vigiando e controlando seu trabalho de forma remota. Esses processos elevam seus esforços por meio de diversas cobranças institucionais, por sua auto cobrança, ou mesmo pelo aumento de alunos em sala. Além disso, seu trabalho é precarizando pela não aplicação de leis trabalhistas que deveriam ser respeitadas.

Dos seis docentes entrevistados, apenas uma não manifestou interesse em adentrar uma instituição pública. O motivo principal mencionado por eles para esse planejamento a longo prazo é a estabilidade no emprego, já que nas instituições privadas eles sempre têm dúvidas sobre a continuidade de seu trabalho, uma vez que que há cortes frequentes do corpo docente. 
Levando em consideração os relatos dos sujeitos de pesquisa, faz-se relevante que as instituições lancem um novo olhar ao docente, dando-lhes a chance de mostrar seus pensamentos e sentimentos. Cabe a essas instituições zelar por cada um deles e perceber as diferentes manifestações de insatisfação de forma antecipada para desenvolver formas de melhorar as deficiências reveladas pelos relatos no contexto do trabalho docente.

A pesquisa qualitativa realizada por meio da análise das narrativas de histórias de vida permitiu aprofundar os conhecimentos sobre as condições de trabalho dos docentes do ensino superior privado de grandes grupos educacionais, evidenciando aspectos que confirmam a precarização e intensificação de seus esforços dentro e fora das paredes institucionais, permitidas pelo controle remoto de suas atividades. Assim, enquanto as instituições buscarem lucros exorbitantes, será mais difícil fazer com que os professores sejam ouvidos em suas necessidades.

É importante ressaltar que, este estudo não teve como objetivo colocar a privatização como culpada pelo tratamento dispensado aos professores, ou demonizá-la pela piora nas relações trabalhistas entre instituições e docentes. Tratou-se apenas de um debate sobre instituições educacionais que carregam perfis empresariais, geridas com base em uma pressão de mercado que, em determinados casos, têm o lucro como principal preocupação, esquecendo-se da responsabilidade que carregam quando decidem negociar um serviço tão importante quanto a educação. Isso não quer dizer que todas as instituições privadas tenham a mesma visão. Tampouco quer dizer que essas instituições sejam melhores ou piores de se trabalhar que as universidades públicas. Para o desenvolvimento de uma temática assim, um novo e mais amplo estudo precisaria ser realizado.

Almeja-se que os resultados desta pesquisa possam alicerçar novas reflexões, discussões e possíveis intervenções no ambiente acadêmico, contribuindo para um pensar em conjunto de forma a aprimorar as relações de apoio ao docente. Uma sugestão para a continuidade deste estudo seria uma pesquisa com maior amostragem de docentes de cada um dos maiores grupos educacionais com atuação em Belo Horizonte, para que haja uma discussão aprofundada sobre os pontos aqui descritos. Outra sugestão de continuidade de estudos, seria conhecer a percepção dos discentes a respeito da mercantilização das instituições de ensino em que estudam. Outra ideia ainda, seria a comparação da percepção de docentes de instituições públicas e privadas, para caracterizar o trabalho dos docentes em cada uma delas. 


\section{REFERENCIAS}

ARAÚJO, M. G. B. Sociedade de controle e capitalismo rizomático. Revista Critério, v. 06, 2006.

BALL, S. J. The education debate. Bristol: The Policy Press, 2009.

BARDIN, L. Análise de Conteúdo. Lisboa: Ed. 70, 1979.

BENDASSOLLI, P F. Trabalho e identidade em tempos sombrios: insegurança ontológica na experiência atual com o trabalho. Ideias \& Letras, Aparecida, S.P., 2007.

BEST, K. Living in the control society: Surveillance, users and digital screen technologies. International Journal of Cultural Studies, Thousand Oaks, v. 13, n. 1, p. 5-24, 2010.

BOLTANSKI, L; CHIAPELlO, È. O novo espírito do capitalismo. São Paulo: Editora WMF Martins Fontes, 2009.

BOSI, A. P. A precarização do trabalho docente nas instituições de ensino superior do Brasil nesses últimos 25 anos. Educação e Sociedade, Campinas, vol.28, n. 101, p. 1503-1523, set./dez., 2007.

BOSI, A. P. Precarização e intensificação do trabalho no Brasil recente: ensaio sobre o mundo dos trabalhadores (1980-2000). Cascavel: Edunioeste, 2011.CARVALHO, C. H. A. A mercantilização da educação superior brasileira e as estratégias de mercado das instituições lucrativas", Revista Brasileira de Educação, vol.18, n.54, 2013, pp. 761-776.

CHAUÍ, M. A universidade pública sob nova perspectiva. Revista Brasileira de Educação. São Paulo, n 24, p. 5-15. 2003.

CLOSS.L.Q.; ANTONELLO, C.S. o uso da história de vida para compreender processos de aprendizagem gerencial. Revista de Administração Mackenzie, v. 12, n. 4, São Paulo, jul./ago. 2011.

CORIAT, B. "France: un fordisme brisé mais sans successeur" , In: Boyer R., Saillard, Y. (Orgs.), Théorie de la regulation. L'état des savoirs, Paris, La Décourte, p. 389-97, 1995.

DAHL, R. A. Sobre a democracia. Brasília, EdUnB, 2001. 230p.

DEJOURS, C. A loucura do trabalho: estudo de Psicopatologia do Trabalho. São Paulo: Cortez, 1998.

DEMO, P. Escola pública e escola particular: semelhanças de dois imbróglios educacionais. Avaliação e Políticas Públicas em Educação, v. 15, n. 55, p. 181-206, abr./jun., 2007.

DENZIN, N. K. The research act: a theoretical introduction to sociological methods. 3 ed. Englewood Cliffs NJ: Prentice Hall, 1989.

ESPEJO, M. M. S. B.; PREVIDELLI, J. J.. As estratégias do empreendedor do ensino superior privado diante das políticas públicas para este empreendimento: algumas 
reflexões.

2005

Disponível

em

<http://www.icesi.edu.co/ciela/anteriores/Papers/ppem/3.pdf> Acesso em 05 ago. 2015.

FERREIRA, P. C. A. S; NASCIMENTO, R. P., SALVÁ, M.N. Professor: Profissão de Risco. Uma análise do Impacto da Gestão de IES Privadas sobre o Trabalho Docente. Revista Sociedade, Contabilidade e Gestão, vol. 09, n. 2 mai./ago., 2014.

FONTANELLA, B.J.B.; RICAS, J.; TURATO, E.R. Amostragem por saturação em pesquisas qualitativas em saúde: contribuições teóricas. Cad. Saúde Pública, Rio de Janeiro, v.24, n.1, 17-27, jan. 2008.

FOUCAULT, M. Vigiar e punir: nascimento da prisão. Petrópolis. Vozes. 288p. 1987.

FRANCO, T; DRUCK, G.; SELIGMANN-SILVA, E. As novas relações de trabalho, o desgaste mental do trabalhador e os transtornos mentais no trabalho precarizado. Revista brasileira de saúde ocupacional, São Paulo, v.35, n. 122, p. 229-248, 2010.

FREIRE, P. Medo e Ousadia. Rio de Janeiro: Paz e Terra, 1986.

FREITAS, M. E. A metáfora da guerra e a violência no mundo do trabalho. São Paulo: FGV, 2006

GOMES, M. T. S. As mudanças no mercado de trabalho e o desemprego em Presidente Prudente/SP - Brasil. Scripta Nova - Revista electrónica de geografía y ciencias sociales. Universidad de Barcelona, v. 6, n. 119. Ago. 2002.

GUIMARÃES, A. R. ; MONTE, E. D.; MORAES, V. S. A expansão da educação superior no Brasil: análise a partir dos Programas nacionais PROUNI e FIES. XX Seminário Nacional UNIVERSITAS/Br: Políticas de educação superior no Brasil - expansão, acesso e igualdade social. Anais... João Pessoa, UFPB, 2012.

HARGREAVES, A. Os professores em tempos de mudanças: o trabalho e a cultura dos professores na Idade Moderna. Lisboa: McGraw-Hill, 1998.

HARVEY, D. Condição Pós-Moderna. 13 ed. São Paulo: Edições Loyola (2005).

HOPER. Bússola Educacional. Resultados de ingressantes em 2016 na educação superior. Disponível em http://www.hoper.com.br/\#!RESULTADO-DE-INGRESSANTES-EM-2016NA-EDUCA\%C3\%87\%C3\%83O SUPERIOR/cupd/57026af70cf2e0dbcac3e38d Acesso em 28 jun. 2016.

INSTITUTO NACIONAL DE ESTUDOS E PESQUISAS ANÍSIO TEIXEIRA - INEP. Censos da Educação Superior. Brasília: INEP, 2012. Disponível em $<$ http://portal.inep.gov.br/superior-censosuperior-sinopse>. Acesso em: 10 set. 2015.

LIBÂNEO, J. C. Pedagogia, pedagogos para quê?. São Paulo : Cortez, 2000.

MAGESTE, G.; LOPES, F. O uso da história de vida nos estudos organizacionais. In: Encontro de ensino e pesquisa em administração e contabilidade, 1., 2007, Recife. Anais...Recife: EnEPQ, p. 1-16, 2007. 
MARTINS, A.A.V.; HONÓRIO, L.C. Prazer e sofrimento docente em uma instituição de ensino superior privada. In: XXXVI Encontro da ANPAD - EnANPAD, 2012, Rio de Janeiro - RJ. XXXVI Encontro da ANPAD - Anais... EnANPAD, 2012.

MENDONÇA NETO, O. R.; ANTUNES, M. T. P.; VIEIRA, A. M. . Dispositivos de controle, vigilância e dressage: a domesticação do trabalho docente. In: Encontro da Associação Nacional de Pós-Graduação e Pesquisa em Administração (ANPAD), 2012, Rio de Janeiro - RJ. Anais do XXXVI ENANPAD, 2012.

MENDONÇA NETO, O. R.; ANTUNES, M. T. P.; VIEIRA, A. M. Controle do trabalho docente: provocações foucaultianas para análise da gestão universitária. Avaliação (Campinas), Sorocaba, v. 20, n. 3, p. 665-683, Nov. 2015.

NOGUEIRA, A.F.M.; OLIVEIRA, M.A.G. Mercantilização e relações de trabalho no ensino superior brasileiro. Rev. Ciênc. Admin., Fortaleza, v. 21, n. 2, p. 335-364,jul./dez. 2015.

OLIVEIRA, D. A.; et al. Transformações na organização do processo de trabalho docente e $o$ sofrimento do professor. Red Estrado. 2010. Disponível em <http://www.redeestrado.org/web/archivos/publicaciones/10.pdf.> Acesso em: 8 nov. 2015.

OLIVEIRA, E. S. G. O. Mal-estar docente como fenômeno da modernidade: os professores no país das maravilhas. Revista Ciências \& Cognição, Rio de Janeiro, v. 7, p. 27-41, 2006.

PASTRÉ, O. Taylorisme, Productivité et crise du travail, Travail et emploi, n. 18, outubrodezembro, 1983, pp. 43-70.

QUEIROZ, M. I. P. Variações sobre a técnica do gravador no registro da informação viva. São Paulo: T. A Queiroz, 1991.

SANTANA, M. A. O mundo do trabalho em mutação: as reconfigurações e seus impactos. Cadernos IHU Ideias (UNISINOS), São Leopoldo, v. 34, p. 1-22, 2005.

SENO, J. P.; KAPPEL, L. B. VALADÃO JR. V. M. As percepções do professor universitário da área de gestão acerca das mudanças na educação superior: uma pesquisa com profissionais de instituições de ensino privadas do Triângulo Mineiro. Gestão e Regionalidade, v.30, n 88. 2014.

SEWELL, G.; WILKINSON, B. Someone to watch over me: surveillance, discipline and the Just-in-Time labour process. Sociology, London, v. 26, n. 2, p. 271-289, 1992.

SILVA JR, J. R.; SGUISSARDI, V.; PINTO E SILVA, E. Trabalho intensificado na universidade pública brasileira. Universidade e Sociedade, 45(9), 9-25. jan., 2010.

SILVA, D. B.; SILVA R. M.; GOMES, M. L. B. O reflexo da terceira revolução industrial na sociedade. XXII Encontro Nacional de Engenharia de Produção. Curitiba, out., 2002. 
THERRIEN, J.; CARVALHO, A. O professor no trabalho: epistemologia da prática e ação / cognição situada - elementos para a análise da práxis pedagógica. Revista Brasileira de Formação de Professores, Belo Horizonte, v. 1, p. 129-147, 2009.

TUMOLO, P. S. ; FONTANA, K. B. Trabalho Docente e Capitalismo: um estudo crítico da produção acadêmica da Década de 1990. Revista Trabalho Necessário, ano 6, número 6, 2008 .

XING, Y.; SIMS, D. Leadership, daoistwuwei and reflexivity: flow, self-protection and excuse in Chinese bank managers' leadership practice. Management Learning, 43(1), 97112., 2012. 